\title{
Calculation of the Thermal Stress when Subjected to an Electric Current on Glass and Carbon Fibers with Copper Coatings
}

\author{
$S$. Fedorov ${ }^{1, *}, D$. Borisov ${ }^{1}$, and $V$. Nelyub ${ }^{1}$ \\ ${ }^{1}$ Bauman Moscow State Technical University (BMSTU), 105005, Moscow, Russia
}

\begin{abstract}
Two types of fibers (carbon and glass) are considered, as an object of research,on the surface of which a copper coating is applied with a thickness of $100 \mathrm{~nm}$ using magnetron sputtering technology.A finite element model of a coated fiber was built and simulated in the COMSOL Multiphysics software.As a result of the calculations, the values of the temperatures, arising during the passage of electric current on the surface of the fibers and copper coating, have been determined. This calculation makes it possible to simulate the thermal heating modes occurring in parts of fiberglass and carbon fiber reinforced plastics in the process of curing. As a result of calculations, it was found that copper coating significantly improves electrical conductivity, which is especially important for glass fibers, since its conductivity is considerably lower than carbon. The use of copper coating in the production of parts from fiberglass allows to regulate their thermophysical properties within a wide range.
\end{abstract}

\section{Introduction}

Polymer composites based on fibred carbon materials and epoxy resins are widelyused in the production of rocket-space engineering, the aircraft industry, mechanical engineering, in the production of road and construction machines, etc.[1-4].They are used in the manufacture of structural elements, which require a combination of high strength, rigidity, durability and minimum weight [5-9].Currently, in the manufacture of parts from carbon fiber reinforced plastics, prepreg technologies and methods of direct molding are used [1012].The principle of direct molding methods is that the process of impregnating the reinforcing compound and the molding processof the partare combined into a single technological operation. This leads not only to a reduction in the duration of part manufacture, but also to a reduction in energy and labor costs and, as a consequence, reduce the cost of technology.Direct molding methods include: vacuum infusion, resin transfer molding (RTM), resin film infusion, etc.

The choice of molding technology for parts made of carbon fiber depends on a set of factors relatedto the configuration of the geometric shape, its dimensions, the required accuracy, serial production, the properties of the materials (matrix and compound), etc. Due to high cost of composite tooling, pressure impregnation technology used in the

*Corresponding author: sfedorov@emtc.ru 
manufacture of small size pieces in serial production. Vacuum infusion technology is used in a single or small-scale production in the parts manufacture of various geometric shapes and sizes.

Carbon composites have unique thermophysical properties, high biological and chemical fastness. A large variety of carbon fiber and difficult operating conditions makes it necessary to improve the operational characteristics of existing materials, requiring complex expand their properties.Various technologies are used to modify the properties of carbon fabrics: oxidation, glazing (finishing), electroplating treatment, etc. It is also effective to use the method of magnetron sputtering, which is a universal ionic method, which allows to modify not only metallic, but also nonmetallic materials $[12,13]$.The essence of the magnetron sputtering method is the bombardment of the cathode with argon ions. In the near-cathode area, a zone of crossing magnetic and electric fields is formed, and the electrons in this region ionize the gas, which leads to the appearance of a glow discharge with the formation of plasma. The positive ions of the working gas are accelerated towards the cathode, bombarding its surface. The atoms of material ejected from the target surface are deposited in form of a film on the substrate, wherein as used in this work carbon tape. The main advantage of the magnetron sputtering technology is the low temperature of the plasma and the substrate, which does not damage the substrate material and ensures high sputtering quality.

By adjusting the chemical nature and thickness of the metal coating, it is possible to vary the thermophysical characteristics of reinforcing materials and composites based on them within a wide range. The authors of studies have shown thatit is expedient to use copper with a thickness of $100 \mathrm{~nm}$ as a metal coating material $[9,14]$.

The aim of this work is to develop a model of a copper-clad fiber and to determine the thermal loads when exposed to an electric current.It will alloy to evaluate their electrical conductivity and define the areas of application of the metallization technology for fibers of different chemical nature.The electrical conductivity of reinforcing materials has a significant effect on the kinetics of the heating process of parts madeof glass- and carbonfiber in the process of curing.This is especially true for glass fibers, which have significantly lower thermophysical properties.

\section{Discussion of researchresults}

In the COMSOL Multiphysics environment, a three-dimensional model of the investigated fiber was created (Fig. 1) with a variable diameter of 6-7 microns and a copper film along the entire perimeter with a thickness of $200 \mathrm{~nm}$. The model comprises a thinning in central fiber to create sections with increased resistance, which will evaluate the maximum heating fibers concentrated in the art.

After constructing the geometry, the physical properties of the used fibrous materials were set (Table 1) [15]. The physical properties of carbon are taken close to the state of graphite, since the final stage in the production of carbon fiber is graphitization. The properties of the glass correspond to the characteristics of high modulus high strength (HMP) glass fiber, which is a reinforcing material for highly stressed structures.

Table 1. Physical properties of materials

\begin{tabular}{|l|c|c|c|}
\hline Setting & Carbon & Glass & Copper \\
\hline Electricalconductivity, S / m & $3 \cdot 10^{3}$ & $1 \cdot 10^{-11}$ & $5.95 \cdot 10^{7}$ \\
\hline Specific heat, J/ $\mathrm{kg} \cdot \mathrm{deg})$ & 710 & 840 & 385 \\
\hline Density, $\mathrm{kg} / \mathrm{m} 3$ & 1950 & 2700 & 8960 \\
\hline Thermal conductivity, W / (m $\cdot \mathrm{deg})$ & 150 & 1 & 400 \\
\hline
\end{tabular}


Next were specified electrical and thermal film contacts with the surface of the fiber.A current was applied to one end of the fiber, and the other end was grounded.The standard COMSOL Multiphysics functions generated a computational mesh with tetrahedral elements of various sizes. This form of elements is standard and also is suitable for most in the COMSOL environment. The size of the grid elements was adjusted manually: for carbon fiber, it ranged from 115 to $600 \mathrm{~nm}$; for a thin copper film, the average size of the tetrahedron side was $115 \mathrm{~nm}$ (Fig. 2).

Earlier, the authors of [13] found that the average current per fiber in the composition of the reinforcing fabric during a lightning strike is from 0.1 to $1 \mu \mathrm{A}$.After that, a significant number of calculations were carried out for heating carbon and glass fibers with and without a copper coating at various currents.As expected, the cross-section of the fiber with the smallest area in the middle of the model has the highest heating temperature (Fig. 3).

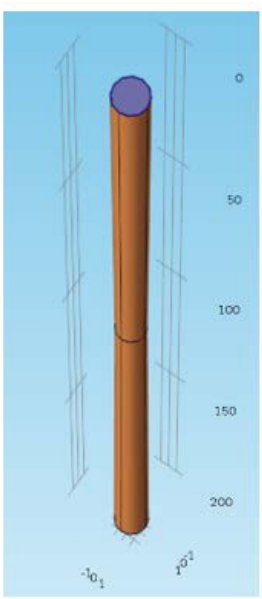

a)

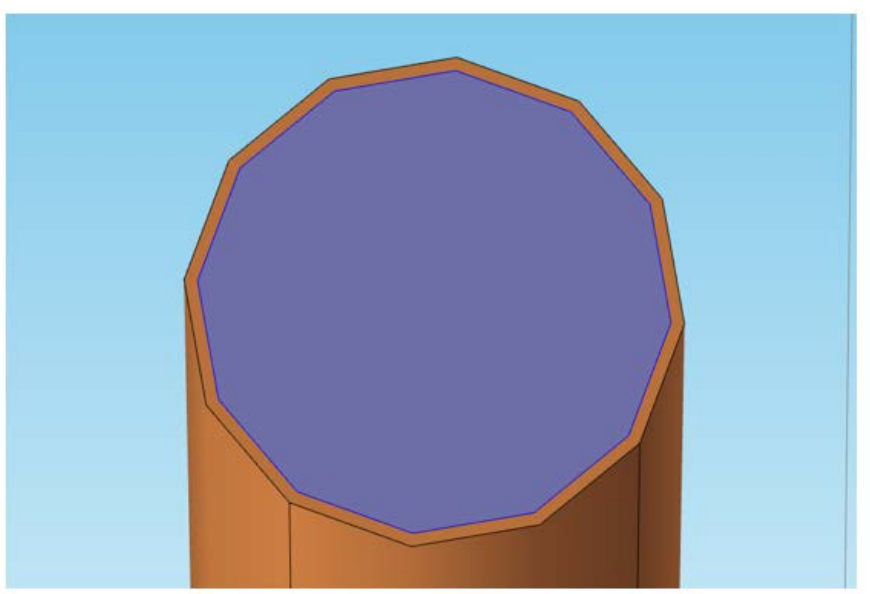

b)

Fig. 1. Three-dimensional model of carbon fiber (a) and its cross-section (b), made in the COMSOL Multiphysics environment

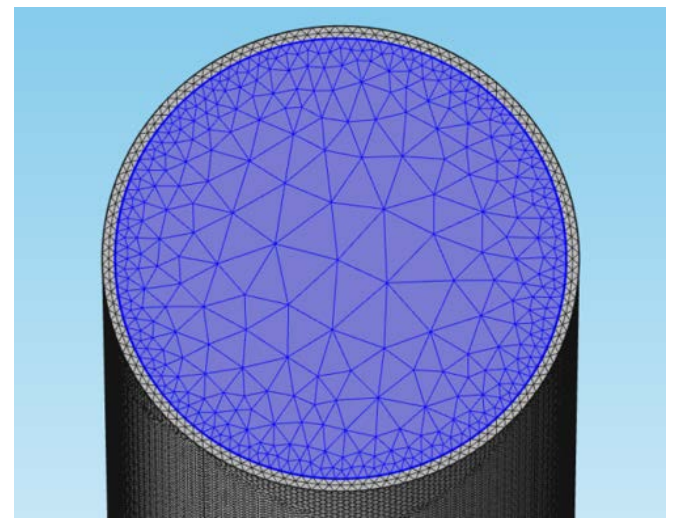

Fig. 2. Cross-section of coated carbon fiber with finite element designation 


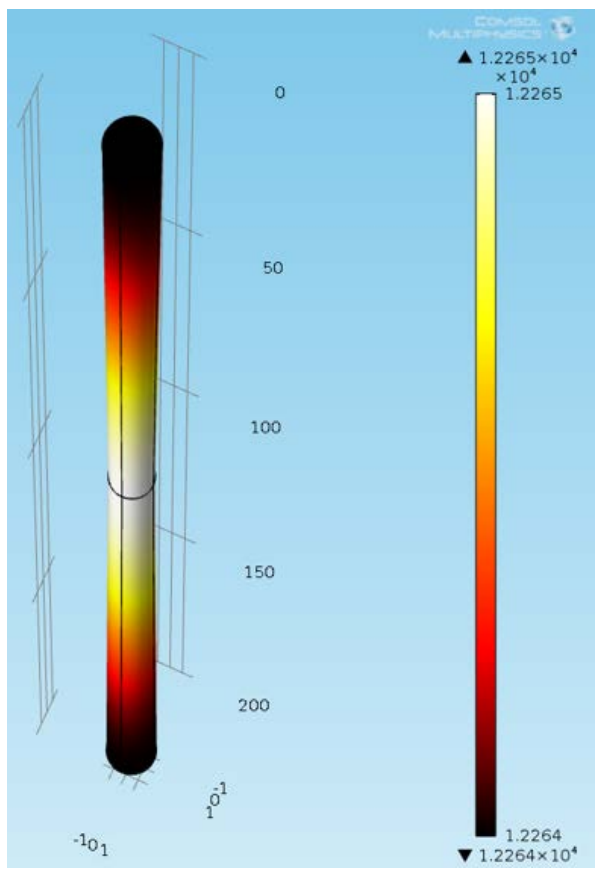

Fig. 3. Calculation results with the designation of the temperature distribution over the carbon fiber surface

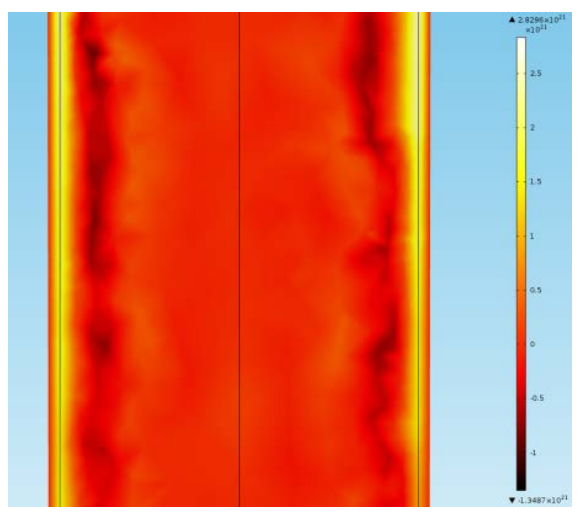

a)

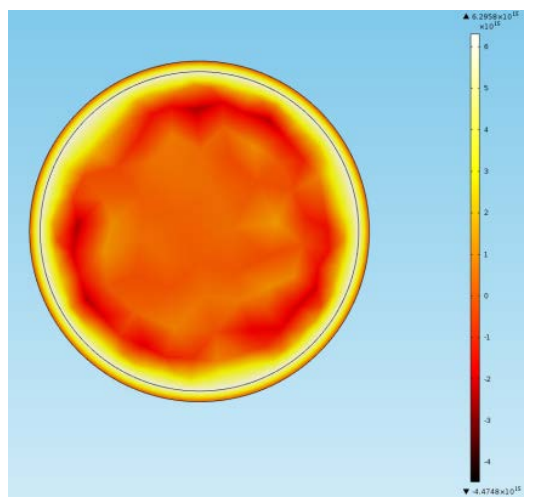

b)

Fig. 4. Cross-section of carbon fiber with copper coating along (a), and perpendicular (b) to the axis of symmetry of the model

The results obtained make it possible to estimate the distribution of temperature fields in the cross section of the reinforcing fiber: a thin copper film heats up slightly more than a fiber when an electric current is passed through it: no more than 1\% (Fig. 4).

For convenience in comparing the results obtained, they are shown in Fig. 5. They characterize the heating temperature of carbon and glass fibers when an electric current passes through it with and without a copper coating. 


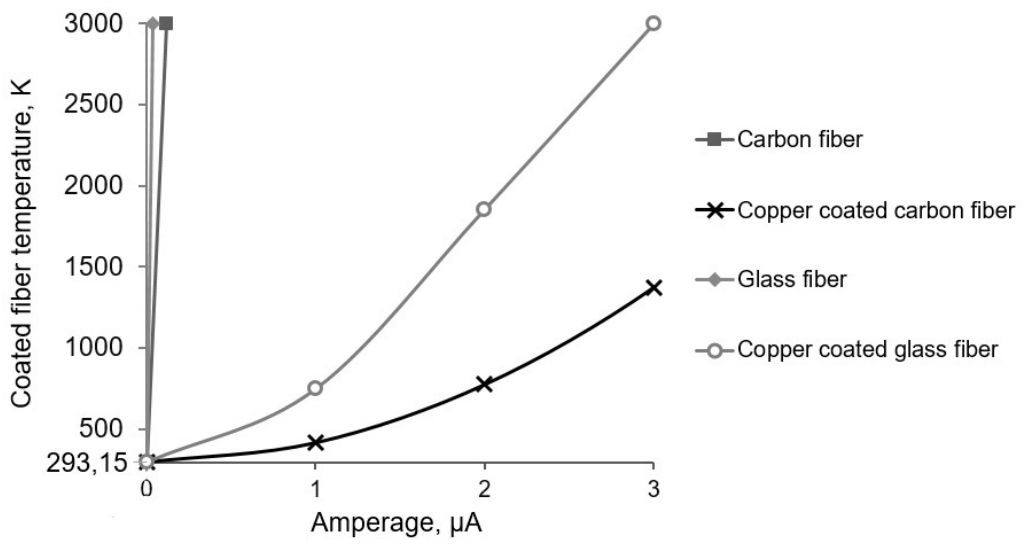

Fig. 5. Dependence of the heating temperature of carbon and glass fiber with and without copper coating of amperage

As a result of the calculations, it was found that in the absence of a metal film, the fibers are characterized by an avalanche-like increase in the temperature of the fiber with an increase of amperage.The expected difference appears when comparing the heating of carbon and glass fibers due to the increased resistance of the glass fiber.The thin copper film provides significant advantage in the form of a conductive layer for each type of the studied fibers and it also reduces the resistance of the sample.In the presence of a copper coating, the charge flows down with less resistance due to the high electrical conductivity of copper, even with a minimum film thickness.

Analysis of the results shows that there is a noticeable decrease in the heating temperature for both types of fibers. The obtained values have little difference even with different base materials. This fact suggests that the main part of the electric current in the presence of a metal coating goes through the film bypassing the fiber.

\section{Conclusions}

As objects of research, two types of reinforcing materials are reviewed: glass and carbon fibers, which are widely used in parts manufacture from polymer composite materials.In terms of their thermophysical properties, glass and carbon fibers differ significantly from each other, which substantially complicates the development of technological modes of their curing.To regulate the thermophysical properties of glass fibers, it is proposed to apply copper coatings to their surface.

It is proposed to apply the copper coating by the method of magnetron sputtering, which makes it possible to obtain a uniform thin layer on the surface of fabrics and slubbing.

A fiber model has been constructed with a copper coating on its surface. It was found that the heating rate of copper-coated and uncoated glass fibers differ by several orders of magnitude.Glass fiber with copper coating in its thermophysical properties is close to carbon fiber with a similar coating.

The calculation results confirm the validity and effectiveness of the metallization technology of reinforcing fibers in order to increase the electrical conductivity.Copper gives a significant increase in the electrical conductivity of the fiber and turns out to be an effective solution to protect it from overheating when an electric current is passed through it. 
The results of this work were obtained within the framework of agreement No. 19/1251/2021 dated $30,04,2021$ (On the provision of a grant for state support to the centers of the National Technology Initiative on the basis of educational institutions of higher education and scientific organizations).

\section{References}

1. Baurova N.I., Makarov K.A.Machining of machine elements made of polymer composite materials.Rission Metallurgy. №13. pp..1141-1144. (2017).

2. KonoplinA.Yu., Baurova N.I. Hardness of the near-weld zone during contact spot welding of steels using an adhesive-weld technology. Russian Metallurgy. № 13. pp.1308-1311. (2016).

3. Baurova N., Anoprienko A., Romanova Y. Providing dismountable rivet bonded joints through the use of hot-melt adhesive. ICMTMTE. v. 129. (2017).

4. Gorodetskii M.A., Nelyub V.A., Malysheva G.V., Shaulov A.Y., Berlin A.A. Technology of forming and the properties of reinforced composites based on an inorganic binder. Russian Metallurgy, v. 13. pp.1195-1198. (2018).

5. Maung P.P., Malysheva G.V. Modeling the effect of fabric weaving pattern on the kinetics of the impregnation process in the manufacturing of the fiber reinfocced plastic structures. AIP Conference proceeding. v.2171. (2019).

6. Marycheva A.N., Guzeva T.A., Pe P.M., Tun L.K., Malysheva G.V. Technologies of production of layered composites // Russian Metallurgy. №13. pp.1373-1377. (2019).

7. Sergeyev A.Y., Turusov R.A., Baurova N.I., Kuperman A.M. Stresses arising during cure of the composite wound on the cylindrical surface of an element of exhaust system.Mechanics of Composite Materials. 51(3). pp.321-332. A006. (2015).

8. Sergeev A.Y., Turusov R.A., BaurovaN.I.Strength of the Joint of an Anisotropic Composite and a Cylindrical Element of the Exhaust System of Road Vehicles. Mechanics of Composite Materials. 52(1). pp.89-98. (2016).

9. Baurova N.I., Zorin V.A., Prikhodko V.M. Influence of structural defects in carbon fibers on their sensor properties evaluated using scanning electron microscopy. Fibre Chemistry. v.46. №5. pp.283-287. (2015).

10. Kosenko E.A., Baurova N.I., Zorin V.A. Service properties of composites with various types of hybrid matrices. Russian Metallurgy (Metally). №13. P. 1526-1530. (2020).

11. Kobets L.P., Borodulin A.S., Malysheva G.V. Study of microcapillary impregnation of carbon fibres by epoxy binders. Fibre Chemistry. 48(4). pp.311-315. (2016).

12. Borodulin A.S., Marycheva A.N., Malysheva G.V. Simulation of impregnation kinetics of fabric fillers in the production of fiberglass articles. Glass Physics and Chemistry, v. 41(6). pp. 660-664. (2015).

13. Nelyub V.A., Gorberg B.L., Grishin M.V., Berlin A.A., \& Malysheva G.V. Properties and technology of applying metal coatings to carbon tape. Fibre Chemistry, v. 50 (6). pp. 524-527. (2019).

14. Nelyub V.A. Technologies of metallization of carbon fabric and the properties of the related carbon fiber reinforced plastics. Russion Metallurgy. № 13. pp.1199-1201. (2018).

15. GOST R 8.941-2017. Standard reference data. Materials for reference measures of the thermal coefficient of linear expansion. Graphite grade GIP-4. Enter. from 01.03.2018 to the present - Moscow: Standartinform, 2018 .11 p. 